\title{
INFLUENCIADORAS DE MODA EM VITÓRIA DA CONQUISTA, BAHIA, BRASIL: CONTINUIDADES E DESCONTINUIDADES
}

\author{
INFLUENCERS DE LA MODA EN VITÓRIA DA CONQUISTA, BAHÍA, \\ BRASIL: CONTINUIDADES Y DISCONTINUIDADES
}

\begin{abstract}
FASHION INFLUENCERS IN VITÓRIA DA CONQUISTA, BAHIA, BRAZIL: CONTINUITIES AND DISCONTINUITIES
\end{abstract}

DOI: $10.22481 /$ rbba.v10i01.8823

\author{
Heloar Vasconcelos Ribeiro \\ Universidade Estadual do Sudoeste da Bahia (UESB) \\ ID Lattes: http://lattes.cnpq.br/4468182799034058 \\ Endereço eletrônico: heloarvr@gmail.com \\ Maria Salete de Souza Nery \\ Universidade Federal do Recôncavo da Bahia (UFRB) \\ ID Lattes: http://lattes.cnpq.br/9960252288161744 \\ ORCID: https://orcid.org/0000-0002-7723-2243 \\ Endereço eletrônico: saletenery@ufrb.edu.br
}

\begin{abstract}
RESUMO
O objetivo desta pesquisa é o de analisar continuidades e descontinuidades no processo de influência e produção/reprodução de gostos a partir de influenciadoras digitais de moda de Vitória da Conquista (Bahia, Brasil) e sua relação com outras influenciadoras conhecidas nacionalmente e com o comportamento de mulheres conquistenses na década de 1960. O estudo foi realizado a partir de pesquisa bibliográfica, realização de entrevistas junto às influenciadoras da cidade, reportagens sobre a história da cidade nos anos 1960, além de entrevistas com
\end{abstract}




\section{INFLUENCIADORAS DE MODA EM VITÓRIA DA CONQUISTA, BAHIA, BRASIL: CONTINUIDADES E DESCONTINUIDADES}

mulheres pertencentes a famílias mais abastadas que viveram nesse período ou têm lembranças sobre ele. Concluímos que é possível tratar a influência digital não apenas como um novo momento de relações pautado no incremento tecnológico (descontinuidade), mas também como prolongamento de mecanismos sociais de distinção nos gostos e relações de influência a partir das hierarquizações instituídas previamente nas redes sociais digitais (continuidade).

Palavras-chave: Influenciadoras digitais; moda; continuidades; descontinuidades.

\section{RESUMEN}

El objetivo de esta investigación es analizar continuidades y discontinuidades en el proceso de influenciar y producir/reproducir gustos a partir de influencers de moda digital de Vitória da Conquista (Bahia, Brasil) y su relación con otras personas conocidas a nivel nacional, en la actualidad, y con el comportamiento de mujeres de la ciudad en la década de 1960. El estudio se llevó a cabo a partir de investigaciones bibliográficas, entrevistas a influencers de la ciudad, informes sobre la historia de la ciudad en la década de 1960, así como entrevistas a mujeres pertenecientes a familias más adineradas que vivieron en ese período o tengo recuerdos de él. Concluimos que es posible tratar la influencia digital no solo como un nuevo momento de relaciones basado en el incremento tecnológico (discontinuidad), sino también como una extensión de los mecanismos sociales de distinción en gustos y relaciones de influencia desde las jerarquías establecidas con anterioridad a las redes sociales digitales (continuidad).

Palabras clave: Influencers digitales; moda; continuidades; discontinuidades.

\footnotetext{
ABSTRACT

The objective of this research is to analyze continuities and discontinuities in the process of influencing and producing/reproducing tastes from fashion digital influencers in Vitória da Conquista (Bahia, Brazil) and their relationship with other nationally known ones, nowadays, and with the behavior of women from this city in the 1960s. The study was carried out based on bibliographic research, interviews with influencers in the city, reports about the history of the city in the 1960s, as well as interviews with 
women belonging to wealthier families who lived in that period or have memories about it. We conclude that it is possible to treat digital influence not only as a new moment of relationships based on technological increase (discontinuity), but also as an extension of social mechanisms of distinction in tastes and influential relationships from the hierarchies established prior to digital social networks (continuity).

Keywords: Digital influencers; fashion; continuities; discontinuities.

\section{INTRODUÇÃO}

Influenciadores e influenciadoras digitais se tornaram uma espécie de fenômeno a revolver os mecanismos mais convencionais de relacionamento, transmissão de gostos e de marketing pelo uso, e modo de uso, das redes sociais. Uma das áreas de forte atuação de influenciadores e influenciadoras é a moda, que constitui importante segmento de mercado no mundo do consumo e dos consumidores. Contudo, a despeito das inegáveis novidades advindas da era das redes, busca-se aqui discutir as digital influencers (influenciadoras digitais) de moda também a partir da perspectiva de uma continuidade de atuação de mulheres que se tornam e se colocam, ou são colocadas, como referências de gosto, conectando pessoas pela circulação e organização hierarquizada de gostos e usos que ajudam a disseminar, algo anterior à disseminação das redes digitais.

A partir da união entre os temas moda e mídias sociais, podemos problematizar os instagrans de moda como espaço cibernético em que um estilo de vida é seguido, ou ao menos almejado, considerando o crescente número de homens e mulheres de vários países que tomaram para si um comportamento de bloggers, evidência de seu desejo de acumular seguidores, presentes e parcerias com grandes marcas de roupas, acessórios e cosméticos, além de viagens patrocinadas para destinos nacionais e internacionais e, é claro, o retorno financeiro que t essa visibilidade tem possibilidade de trazer.

Moças de Vitória da Conquista, cidade do interior da Bahia (estado situado na região nordeste do Brasil), também passaram a compor essa rede, atualizando informações de moda a partir de suas influenciadoras digitais de referência, ao mesmo tempo em que trazem novos conteúdos para alimentar a rede. No entanto, podemos questionar: apesar das notórias inovações 


\section{INFLUENCIADORAS DE MODA EM VITÓRIA DA CONQUISTA,}

BAHIA, BRASIL: CONTINUIDADES E DESCONTINUIDADES

trazidas pelo desenvolvimento da técnica para a comunicação interpessoal, seria possível perceber continuidades na visada do processo histórico do qual as digital influencers emergem enquanto pessoas que se tornam polos na constituição dos gostos de outras jovens?

A partir dessas reflexões, este artigo tem como objetivo analisar as continuidades e descontinuidades no processo de influência e produção/reprodução de gostos a partir da atuação das influenciadoras digitais de moda da cidade de Vitória da Conquista atualmente, em relação a mulheres desse município que foram tomadas como referência de moda e estilo na década de 1960, período de expansão comercial da cidade. Ressalte-se que o município, em 1950, era a cidade que mais crescia na Bahia, segundo apontava o senso do IBGE (Instituto Brasileiro de Geografia e Estatística), revelando que, nesse período, a população da cidade era de 79.889 habitantes.

A cidade também torna-se "um importante entreposto comercial e a exercer maior influência nas relações mercantis em virtude das novas vias de comunicação abertas na década de 1940, como a BR 116 (Rio-Bahia) e o trecho rodoviário Ilhéus-Lapa” (SILVA, 2009, p. 2), fatores que contribuíram para o desenvolvimento do comércio e, por conseguinte, para a entrada de produtos como vestuário, adornos, perfumaria, entre outros, na cidade (SOUZA, 1999).

Com o intuito de compreender historicamente essas relações de influência em moda em Vitória da Conquista, foram entrevistadas mulheres que pertenceram à chamada "elite conquistense" dos anos 1960, ou seja, que compunham um círculo com elevado capital social e, portanto, eram conhecidas na cidade para além de seu círculo mais estrito de relacionamentos, bem como influenciadoras digitais do hoje, em especial três, escolhidas por direcionarem seus conteúdos a questões de moda e lifestyle, ou seja, que exploram atividades do seu cotidiano, variando entre o trabalho e dicas de lazer. Assim, foram escolhidas Milla Arielle, Ellen Lapa e Enaira Nicoletti, por conta de se apresentarem como as mais atuantes em seu segmento e também pelo número considerável de seguidores (cada uma possuía mais de onze mil seguidores) não só de Vitória da Conquista e região, mas de outros estados brasileiros.

\section{MOÇAS DE FAMÍLIA EM VITÓRIA DA CONQUISTA}

Os anos 1950 e 1960 podem ser pensados como últimos suspiros de um período em que as novidades da moda eram fundamentalmente gestadas por um grupo bastante restrito e quase indiferente aos usos externos de seus pares sociais, a não ser por certo exotismo. Por isso, o 


\section{INFLUENCIADORAS DE MODA EM VITÓRIA DA CONQUISTA, BAHIA, BRASIL: CONTINUIDADES E DESCONTINUIDADES}

nosso recurso às "moças de família" conquistenses como expressão desse momento e, simultaneamente, como mote à compreensão do caráter social da dinâmica de influências existentes num período cujos produtos da moda começaram a chegar com certa facilidade pela posição privilegiada do município. Ao nos debruçarmos nas falas analisadas, verificamos, inicialmente, a forma de transmissão dos conteúdos de moda em um período em que a televisão, o rádio e o cinema ainda estavam em processo de difusão em cidades brasileiras menores, pincipalmente, além da dificuldade de troca de informações com outras localidades.

Heleusa Câmara, uma dessas moças oriundas de família prestigiosa na cidade nos anos 1950 e 1960, ao ser questionada sobre como se dava a aquisição das informações de moda no período, disse que o principal meio para essa difusão eram revistas como Vida Doméstica, Alterosa, O Cruzeiro, Manchete e algumas revistas mexicanas, que traziam modelos usados naquela época, como também moldes para que as roupas pudessem ser copiadas. Ela cita, em específico, uma coluna em $O$ Cruzeiro, escrita e ilustrada pelo estilista brasileiro Alceu Penna, intitulada "Garotas", em que ele se dedicava a adaptar o modo de vestir das estrangeiras para o Brasil e delinear as primeiras características de uma suposta identidade brasileira.

Ela menciona ainda a Manequim, a primeira revista de moda da Editora Abril, e Burda, revista alemã famosa por trazer encartados os moldes para costura. Heleusa diz que, assim como ela, as moças compravam papel de seda para copiar os modelos e estarem vestidas com roupas ligadas à moda europeia. Estar na moda significava investir materialmente na aquisição dos instrumentos que possibilitariam o acesso àquilo que estava em validação como bom gosto. Dois instrumentos ganham destaque, as revistas nacionais e estrangeiras - com destaque para estas últimas, uma vez que os centros de referência de moda estavam fora do Brasil - e as viagens, pois possibilitavam conhecer e adquirir a "última moda".

Assim, também uma hierarquização é estabelecida entre as moças, bem como possíveis relações de concorrência entre elas na busca por uma posição de maior domínio mesmo na fração dominante quanto ao gosto.

Marcia Galvão se vestia de uma maneira muito diferenciada das outras pessoas porque ela gostava de moda, de alta moda, então ela vestia umas roupas que lembravam artistas de cinema, aquelas roupas que a gente via mais assim em revista. Ela tinha roupas lindas, às vezes até um pouco assim extravagantes, mas eram roupas lindas. Ela era uma mulher belíssima, era muito bonita fisicamente, tinha uma altura muito boa e se vestia muito bem. Então, Márcia era uma referência aqui. (Entrevista realizada com Tonia Viana, 2017). 


\section{INFLUENCIADORAS DE MODA EM VITÓRIA DA CONQUISTA, BAHIA, BRASIL: CONTINUIDADES E DESCONTINUIDADES}

Sobre as referências daquele período, as entrevistadas falam sobre Márcia Galvão, considerada a mulher mais elegante de Vitória da Conquista. Casada com Ademar Galvão, relata-se que ela demonstrava ter muito cuidado com a escolha das roupas e se interessava em vestir-se como a moda vigente. Heleusa conta que Márcia Galvão chegava sempre minutos antes de começar a sessão no Cine Conquista e todos ficavam aguardando sua chegada para ver o que estava usando. No dizer da entrevistada, "seus vestidos eram muito bonitos, ela era uma moça muito bonita, alta, elegante, uma pessoa muito simpática [...] era considerada uma das mais elegantes. Ela consegue sair n'O Cruzeiro, numa página n'O Cruzeiro, que era essa revista famosa" (Entrevista realizada com Heleusa Câmara em 2017). Apesar de Márcia Galvão, todas também queriam ser portadoras da novidade:

[...] Nós éramos tocadas pelas revistas e ninguém queria ter vestido igual à outra. Todo mundo gostaria de ser aquela que trazia a primeira roupa. Quando eu estudei em São Paulo, foi engraçadíssimo, eu trouxe uma saia de príncipe de gales, que foi um tecido muito especial. A minha saia era plissada. Eu trouxe o ban-lon, que era um conjunto twin-set que as pessoas usavam muito em São Paulo, porque eu estudei em um colégio de elite. Eu tinha colegas do Jardim Europa, do Morumbi, Jardim América, e no Mackenzie não usava uniforme, nós íamos de roupa, por isso minha mãe mandava Elzo fazer as minhas roupas para que eu usasse no colégio. (Entrevista realizada com Heleusa Câmara, 2017).

Depreendem-se dessas falas duas questões importantes para pensarmos os elementos de continuidades e descontinuidades de 1950-1960 em relação à atualidade. Primeiro, a forma como os meios de comunicação ajudam na difusão e legitimação do que é a moda vigente, além da diferença entre as revistas que chegavam ao município com um certo atraso e a rapidez com que as informações veiculadas pela internet acontece nos dias de hoje. Apesar das inegáveis mudanças no modo de transmissão dos conteúdos, não podemos deixar de assinalar a necessidade de mecanismos de legitimação para as informações, a fim de que elas possam chegar às pessoas tidas como referência e, se for o caso, atingir as demais.

O fato ainda de acionarmos "moças de família" nesta pesquisa é por considerarmos que eram as principais responsáveis por trazer a moda de cidades maiores, por "reproduzir as roupas das mulheres de Salvador", capital da Bahia, ir ao cinema e copiar os modelos das atrizes e levar para as costureiras, bem como difundir o que liam sobre moda em revistas como $O$ Cruzeiro, Jornal das Moças, Fatos e Fotos, etc., e participar dos concursos e desfiles de moda que aconteciam na cidade, como, por exemplo, os desfiles da Bangu, onde quem participava e 


\section{INFLUENCIADORAS DE MODA EM VITÓRIA DA CONQUISTA, BAHIA, BRASIL: CONTINUIDADES E DESCONTINUIDADES}

quem assistia estava circunscrito a um grupo específico, pois as moças escolhidas eram, frequentemente, as "moças de família irmãs" de Heleusa Câmara e Tonia Viana, como elas mesmas nos relataram. De qualquer modo, através de tais eventos, era escolhida a moça mais bonita e a indumentária, indubitavelmente, constituia elemento de construção da beleza. Ser bonita e estar bonita confundem-se com estar em dia com a mais recente moda e ter a possibilidade de desfrutar uma "vida interessante".

Não queremos, com isso, dizer que apenas as moças pertencentes às famílias mais abastadas se relacionavam com a moda de maneira a figurar como referências, entretanto, ao recorrer às fontes primárias e ao ter acesso a pessoas que puderam relatar sobe o tema naquele período, percebemos que, por uma questão de influências e possibilidades, elas eram as que mais “apareciam". Seguramente, podemos afirmar que as filhas das costureiras da época e tantas outras moças de famílias menos favorecidas economicamente tinham acesso às referidas revistas de moda e também se vestiam em conformidade com os gostos vigentes, contudo, as fontes nos levam a um caminho diverso e, portanto, direcionamos a abordagem a esse grupo específico que apresentamos aqui.

\section{INFLUENCERS CONQUISTENSES: CONTINUIDADES E DESCONTINUIDADES}

Percebe-se um crescente número de influenciadoras digitais na cidade de Vitória da Conquista, comportamento que acompanha o cenário nacional, e até mesmo mundial, no que diz respeito as mídias sociais. Nesse contexto, as entrevistas foram realizadas com as influencers conquistenses Ellen Lapa (10.100 seguidores), Milla Arielle (11.200 seguidores) e Enaira Nicoletti (12.400 seguidores), selecionadas a partir do número de seguidores no Instagram $^{\mathrm{i}}$ e também pelo conteúdo com o qual trabalham, a saber: moda, estilo de vida, viagens, beleza, maquiagem, etc.

A primeira entrevistada, Ellen Lapa, 28 anos, tem o perfil no Instagram há 3 anos e possui graduação em Jornalismo. Ellen explica que seu interesse em se inserir no universo blogger começou a partir do incentivo de amigos e pessoas próximas que a buscavam para informações e dicas sobre variados assuntos. Começou na internet com o Ellen Lapa Blog, onde fazia postagens que variavam entre dicas sobre coisas cotidianas, como destinos de viagens, maquiagem, produtos para cabelo, tendências de vestuário e postagens patrocinadas ou ligadas a parcerias e divulgações de lojas, produtos e serviços da cidade. 
Ellen salienta ainda que há uma necessidade de se manter em visibilidade, e é exatamente por esse motivo que utiliza como critérios para as postagens uma frequência diária no Instagram, principalmente na ferramenta stories. Ela disse que, enquanto blogueira e também como consumidora, percebeu a diminuição da procura pelos blogs, pois ela mesma passou a assistir muito mais vídeos do que ler matérias em blogs, sobretudo por conta da rotina saturada dela e da maioria das pessoas. Por isso se dedicou a oferecer um conteúdo mais visual, em que houvesse mais fotos e em que as legendas fossem mais curtas.

Para Ellen, suas inspirações variam entre bloggers e artistas, celebridades da televisão. Uma das blogueiras que ela mais acompanha e, mais que isso, se inspira é Lia Camargo, que tem mais de dez anos de blog e expõe um estilo de vida mais próximo do que é o cotidiano das pessoas que não são famosas. Acompanha também Camila Coutinho e Bruna Vieira. Ela destacou que "procura blogueiras que pareçam mais reais" e que não se identifica com pessoas que tenham um estilo de vida muito longe da sua realidade. Assim, apesar de manter o gosto próprio com relação a roupas, ela busca influências em outras pessoas.

A respeito do poder de opinião que exerce, Ellen afirmou que existe, mas que seus seguidores não aceitam muito bem a publicidade muito explícita, por exemplo. Ela exemplifica dizendo que não é interessante postar foto apenas do produto, mas sim que ela apareça usando o produto em vídeos ou demonstrando o resultado em fotos de "antes e depois". Ou então, quando em parceria com uma loja, se esta não vende sapatos, ela evita mostrar os pés ou colocar acessórios que atraiam muita atenção e que possam tirar o foco da roupa.

Essas ações detalhadamente pensadas para gerar a influência, vão muito além da virtualidade. As influencers conquistenses, ao afirmarem ter como referências as influenciadoras famosas que são destaque por terem iniciado essa atividade de blogar no Brasil, evidenciam que o conteúdo produzido por elas e o impacto que o mesmo causa em seus seguidores tem um papel que supera a dimensão exclusivamente virtual, pois é uma instância produtora e difusora de socialização que vem para legitimar determinado comportamento dentro de grupos e no processo de construção das identidades.

Assim, as blogueiras-celebridades seriam os agentes preferenciais na constituição de referências para a unicidade do grupo e a formação do modo de agir grupal e individual, e as mídias sociais seriam as instâncias responsáveis pela definição de padrões de legitimidade social e pela dotação da possibilidade técnica de maior circulação de vetores de padronização de gostos e comportamentos. Os estilos de vida das influenciadoras digitais são, portanto, 


\section{INFLUENCIADORAS DE MODA EM VITÓRIA DA CONQUISTA, BAHIA, BRASIL: CONTINUIDADES E DESCONTINUIDADES}

produtos sistemáticos do habitus, sistemas de sinais socialmente qualificados a partir da dialética das condições que são impostas no interior do grupo, refletindo um passado incorporado, um sistema de disposições com possibilidade de funcionar em várias dimensões das práticas culturais, e não somente o meio virtual.

Quando os posts das conquistenses fazem referência a roupa de determinada loja da cidade, que mesmo sendo um post patrocinado também tem um caráter de cotidiano, habitual, elas transmitem algo de individual que é simultaneamente coletivo, que é um estilo próprio de se vestir, ao mesmo tempo em que reproduzem uma prática muito comum das webcelebridades, que é fazer publicidade com roupas de marcas que pagam para estarem atreladas à imagem delas. Inspirando-nos em Pierre Bourdieu (2007), para nós as blogueiras conquistenses seriam agentes que interagem com a realidade social, não sendo tão somente resultado de suas determinações nem capaz de determiná-la, pois nossas estruturas mentais são social e historicamente constituídas: sofrem condicionamentos sociais no momento em que acionamos categorias e percepções compartilhadas que orientam nossas ações e tornamos significativas e igualmente compartilháveis.

Sobre Milla Arielle, é importante dizer que foi uma das pioneiras em relação à atividade de blogger na cidade, porém, atualmente, ela não exerce mais essa tarefa por ter mudado de cidade e ingressado na Faculdade de Psicologia. Apesar disso, é interessante analisar suas falas por conta tanto do seu pioneirismo quanto da percepção de que impulsionou outras pessoas a aderirem à atividade. Ela afirma ter um blog há aproximadamente 10 anos e que a atividade começou de maneira despretensiosa, a partir de seu trabalho de atualização de um site da revista local Revista Conquiste Feminina, que pertencia à sua mãe, a produtora cultural Jeanne Marie.

Milla é formada em Relações Públicas e conta que, nos últimos semestres da faculdade, começou a perceber o interesse das pessoas pelo seu gosto em relação a produtos da moda como roupas e acessórios, além de pedirem a ela com frequência uma espécie de consultoria sobre estilo. A blogueira conta ainda que o site da revista tinha formato de blog, mas não recebia atualizações de forma assídua, então ela começou a fazer publicações referentes ao que era usado pelos artistas: penteados, roupas, marcas mais desejadas, etc. Isso despertou nos lojistas da cidade o interesse por anunciar no site, o que o tornou bastante comercial já no início, como ela mesmo relata:

Eu não tinha nem noção do que cobrar, como cobrar, mas eu fui e coloquei um valor que eu achava que era compatível com o que eu fazia. Aí comecei a visitar as lojas e as lojas foram me procurando. À medida que eu fotografava 


\section{INFLUENCIADORAS DE MODA EM VITÓRIA DA CONQUISTA, BAHIA, BRASIL: CONTINUIDADES E DESCONTINUIDADES}

pra uma, vinha outra loja me procurando [...] Até então não tinha Instagram, era só o Facebook. Tava no início do Facebook, então nem todo mundo tinha e eu nem postava lá . Aí, quando começou a tomar uma proporção maior, eu comecei a postar no Facebook e aí foi crescendo ainda mais com as redes sociais (Entrevista realizada com Milla Arielle em 2017).

Com relação ao número de seguidores, ela disse que foi conseguindo aos poucos, por conta de ter começado em 2009 e o Instagram ainda não existir, tornando mais complicado o trabalho de divulgação e o acompanhamento dos "seguidores". Em sua fala, percebe-se que sua posição privilegiada na cidade, pois vem de uma família de artistas da cidade e de pessoas conhecidas, inclusive por conta da já citada revista que pertencia a sua mãe, a qual divulgava eventos da cidade, fazia anúncios comerciais, etc.. Em seu início de profissão como blogger, o processo de divulgação não tinha a velocidade de agora, pois a leitura de blogs era algo um tanto recente e o Facebook não era acessado por grande número de pessoas como em 2012, por exemplo, onde o número de usuários chegou à marca dos 2 bilhões.

Ela chama a atenção ainda para uma questão muito importante em relação ao número de muito grande de seguidores que alguns influenciadores possuem, pois existem aplicativos para aquisição ou compra dos mesmos, fator que leva as grandes empresas a fazer uma análise dos perfis desses indivíduos nas redes sociais para analisar se os seguidores são "reais" ou não. Milla Arielle exemplifica essa questão relatando o contato que O Boticário, grande empresa brasileira de cosméticos, fez com ela, alegando que, ao analisar o perfil da blogueira, perceberam que seus seguidores não eram "comprados", eram seguidores da cidade, moradores de Vitória da Conquista, mercado que eles gostariam de atingir, por isso a para uma divulgação dos produtos da marca.

Milla conta também que suas influências vieram tanto de pessoas que a incentivavam, quanto de bloggers mais famosas, como Thassia Naves, uma das influenciadoras mais acessadas no Brasil e que possui três milhões de seguidores no Instagram, ou Camila Coutinho (Garotas Estúpidas). Em Vitória da Conquista, Milla disse ter sido influenciada e incentivada por Silvia Khouri, proprietária de uma loja que promovia eventos contando sempre com a participação da blogueira. Além disso, no que diz respeito à vestimenta ou adequação à moda vigente, ela apontou que sempre procurou saber o máximo de coisas possíveis sobre o assunto para criar conteúdo, mas que só usa o que a agrada ou que combina com seu tipo físico, crenças, etc.

Considerando a influência que exerceu, Milla aponta ainda que se considera um pouco responsável pelo surgimento de outras blogueiras em Vitória da Conquista, por conta de ter sido 


\section{INFLUENCIADORAS DE MODA EM VITÓRIA DA CONQUISTA, BAHIA, BRASIL: CONTINUIDADES E DESCONTINUIDADES}

a primeira, ter conseguido visibilidade com grandes marcas, bem como, ter estabelecido uma relação de confiança com muitas lojas da cidade. Quanto a atingir pessoas, ela diz que, no começo, esse alcance não ficou muito perceptível, entretanto, ao postar produtos como roupas e sapatos, recebia um retorno dos lojistas sobre suas postagens. Além disso, salientou que as pessoas também necessitam dessa referência que aponte um caminho a seguir:

Já aconteceu assim, de ter coisa que está lá na loja e que ninguém quer, ninguém vê. "Oh Milla, vê se a gente não faz alguma coisa. Bora montar um look com essa peça pra ver se vende" e vender. Então, assim, era medido no resultado, não tem jeito ou até mesmo alguém vem e fala: "Olha, comprei... cortei meu cabelo igual àquela vez que vi no seu post e gostei". (Entrevista realizada com Milla Arielle em 2017).

Destacamos ainda, sobre ser influenciadora, o que Milla Arielle pensa sobre o assunto, pois a mesma acredita que, atualmente, a influência na internet é exercida mesmo por aquele que não se propõe a isso. Por exemplo, ao postar de forma despretensiosa em seu perfil no Instagram a foto de determinado livro, um indivíduo, certamente, vai incitar o desejo de outros a, pelo menos, conhecer aquele livro, o que pode ser considerado como uma influência. $\mathrm{O}$ mesmo acontece com lugares, roupas, sapatos, viagens, entre outros, e o que diferencia a influenciadora digital tratada nesta pesquisa em relação a outras pessoas é tanto a profissionalização dessa atitude de influenciar, quanto a necessidade que as pessoas têm de pertencer a certo grupo reproduzindo os mesmos hábitos dele, como uma das formas de pertencimento.

Sobre essa afirmação entre a linha tênue da profissionalização e da influência desprenteciosa, Bourdieu nos faz refletir. Apesar de o cenário atual dessa euforia digital não ter sido objeto de estudo do sociólogo francês, arriscamos-nos em uma tentativa de reflexão que alinha, principalmente, seus conceitos de habitus e campo com local específico do ciberespaço, apenas com o objetivo de pensar, à luz desses conceitos, as relações dialéticas e das estruturas e disposições que vão sendo reproduzidas e atualizadas. Assim, destacamos que as plataformas digitais, como o Instagram, atuam como territórios onde diferentes agentes sociais de variados campos se reconhecem a partir de suas afinidades e convergências, ainda que saibamos que a “era digital" é vista e vivida de modos variados pelos diferentes agrupamentos sociais e que a popularização da internet não é garantia de maior democratização e igualdade, podendo tanto contribuir para a manutenção de um habitus de grupo, quanto para o diálogo entre práticas e discursos distintos (BOURDIEU, 2007, p. 165). 


\section{INFLUENCIADORAS DE MODA EM VITÓRIA DA CONQUISTA, BAHIA, BRASIL: CONTINUIDADES E DESCONTINUIDADES}

Enaira Nicoletti, também com 28 anos e formação em Ciências Contábeis, possuía um blog há mais ou menos um ano e sua motivação inicial para a criação do diário virtual foi ter recebido a página de presente de um amigo e também a opinião de pessoas que viam nela a possibilidade de fazer sucesso na blogosfera. Trabalhando com o comércio de roupas há aproximadamente sete anos, a conquistense contou que teve uma experiência inicial a partir do convite que recebeu de uma loja para fazer divulgação de roupas, despertando nela o interesse de aliar esse trabalho com o gosto por produzir conteúdo com a temática moda. Enaira salienta, entretanto, que, no início, não chamava o site de blog e não gostava do título de blogueira, pois tinha preconceito com essa atividade. A entrevistada chama a atenção para questões interessantes, principalmente sobre a forma como as pessoas veem os bloggers:

É porque eu já fui vista como blogueira, eu comecei a ser vista como blogueira $\mathrm{e}$, antes de ser blogueira, eu tinha preconceito, porque eu pensava que era uma coisa e é outra totalmente diferente, porque eu também estudei sobre isso e, hoje em dia, várias pessoas têm uma visão muito ruim sobre o que é ser blogueiro, às vezes as pessoas associam o blogueiro a pedinte e, depois que eu estudei e vi que não era isso, que era bem diferente, que era mais complexo, exigia muito mais coisas do que isso, porque para você ser blogueiro hoje em dia, você tem que ter conteúdo, você tem que ter um histórico, tem que saber apresentar alguma coisa, tem que saber falar sobre ele e várias pessoas hoje em dia são "blogueiros", para isso mesmo, para pedir e receber. (Entrevista realizada com Enaira Nicoletti em 2017).

Em relação a dubiedade sobre "ser blogueiro", a visibilidade que a posição traz em uma cidade interiorana e mesmo os ganhos materiais advindos com a denominação, algumas questões podem ser levantadas. Apesar de nem sempre ser reflexivo e de haver internalizações, podemos afirmar que há imitações pelo desejo de viver a vida de outros ou admirar o modo como se apresentam ou entender que seriam modos mais aceitos pelo público em geral, em especial quando a visibilidade nas redes passa a trazer retornos que conjugam capital simbólico, social e econômico. Como bem relatou a entrevistada Enaira Nicoletti, sobre o fato de muitas pessoas admitirem ter começado o blog para ganhar presentes e tantas outras assumirem a criação de seus perfis nas redes sociais de forma despretensiosa e sem esse objetivo inicial, é possível notar a necessidade, recuperando Bourdieu (2007), de mobilizar, em função própria, a energia simbólica produzida pelos agentes do campo comprometidos em manter seu funcionamento, os quais, no caso dos posts de moda, são aquelas tidas como celebridades, os seguidores que admiram/querem aquele modo de vida, as mídias e grandes marcas que acabam 


\section{INFLUENCIADORAS DE MODA EM VITÓRIA DA CONQUISTA, BAHIA, BRASIL: CONTINUIDADES E DESCONTINUIDADES}

sendo responsáveis pela valorização desses indivíduos, ou seja, todo aparato produtor dessa forma de capital simbólico que produz crença nessa forma de socialidade.

Corrobora ainda com essa discussão a atenção dada por Renato Ortiz (2016) ao termo celebridade e sua tentativa de conhecer o surgimento desse fenômeno. Depreende-se dessa abordagem um fato interessante, quando o autor nos aponta que o termo é recente, moderno, e que traz em si uma dubiedade, um ar de inautenticidade, em que a pessoa célebre seria a cópia do indivíduo que tem verdadeira fama, exatamente por conta dessa expressão, ao menos no inglês, não possuir extensa bagagem cultural. Apesar disso, a celebridade imbrica-se com questões que caracterizam a modernidade como indivíduo, espaço público e meios de comunicação, que necessita tanto para seu reconhecimento quanto para sua individualidade própria pela qual é reconhecida.

E, o que mais importa à nossa discussão, os meios de comunicação conferem às celebridades um caráter de onipresença, como acontece com as influenciadoras de moda, celebridades que não se limitam a tratar, de forma específica, dos produtos da moda - como as vestimentas, sapatos e adornos -, mas também produzem conteúdos sobre restaurantes, cidades e países para visitar, academias de ginástica e personal trainers, chegando aos modos como se posa para uma foto de look do dia. Enquanto a fama traz consigo uma distinção social que coloca os indivíduos dentro de grupos limitados e hierarquizados, com fronteiras bem delineadas, a celebridade atribuída a uma pessoa a coloca em uma distância social que transcende os grupos, pois, como "estão em todos os lugares" a partir do uso que fazem da internet, são acessadas por pessoas de vários segmentos sociais, despertando nestes tanto o desejo de "seguir" esse comportamento como também fazer parte desse rol de pessoas célebres.

Sobre o critério utilizado para “alimentar” as redes sociais, Enaira disse que o Instagram precisa de posts diários e em maior quantidade. Vale relembrar que essa rede social, que se atualiza com grande frequência, permite tanto a postagem de fotos que aparecerão na "linha do tempo" dos seguidores quanto vídeos curtos, que são usados pelas blogueiras para informar sobre sorteios de produtos, conversar sobre o cotidiano, mostrar produtos,roupas e acessórios que estão usando naquele momento ou que receberam de parceiros ou empresas que querem presenteá-las. A utilização desse recurso demonstra uma maior interação entre blogueira e seguidores, pois, ao expor o cotidiano, ela se torna mais próxima daqueles e ainda exibe um modo de vida que desperta o desejo de imitação. O relacionamento com o Instagram é muito 


\section{INFLUENCIADORAS DE MODA EM VITÓRIA DA CONQUISTA, BAHIA, BRASIL: CONTINUIDADES E DESCONTINUIDADES}

importante para Enaira, que considera a entrada em redes sociais uma excelente oportunidade de divulgação do seu trabalho.

Enaira apontou que, antes de tudo, é uma "seguidora", ou seja, acompanha outras pessoas consideradas famosas no universo da blogosfera e uma de suas maiores influências é Gabriela Sales, do Blog Rica de Marré, que se popularizou na rede por conta dos "achadinhos", publicações em que apresenta roupas que estão dentro das tendências da moda, mas com preços acessíveis, principalmente em lojas de fast fashion. Blogueiras famosas e que atingiram um status de celebridades, segundo Enaira, "estão muito no automático", fazem muita divulgação de produtos, posts patrocinados e se distanciaram um pouco da essência de fazer um blog, inclusive delegando a escrita do conteúdo a outras pessoas que compõem sua equipe.

As considerações de Enaira no fazem concorda com Simmel (2008) e Bourdieu (2007) quando apontam para o movimento de imitação e distinção, nos quais ao mesmo tempo em que se quer pertencer a um grupo, também se observa um comportamento de distinção entre eles. Percebemos no comportamento das influenciadoras conquistenses, em relação às nacionais (e internacionais) nas quais costumeiramente se inspiram, que há uma atualização de práticas que trazem consigo a internalização de habitus de grupos que é externalizado como práticas individuais.

Aquilo que liga os gostos, modos de vida, gestos, modos de falar das conquistenses a essas referências externas (nacionais e internacionais) a partir de incorporação/exteriorização de traços nem sempre se dá de modo reflexivo, o que nos leva a sublinhar a noção de memória, enquanto modo de enquadramento social, como um possível elemento-chave na compreensão dessas continuidades-descontinuidades que nos fazem perceber em atitudes singulares algo de familiar, percebido de modo não igual (especificamente imitativo), mas em diálogo com outras práticas - ainda que tal diálogo esteja longe de ser simétrico.

Entendemos ser possível ainda pensar na memória como noção-eixo para compreendermos, do mesmo modo, as continuidades-continuidades que também ligam as atuais influenciadoras àquelas do passado. Moças que funcionam como referências de bom gosto não parecem ser novidades; no entanto, precisamos entender as especificidades do processo em suas descontinuidades. Ao tratarmos de memória, chamamos a atenção para as continuidades-descontinuidades temporais que constituem a história como uma totalidade que não se repete. Há uma articulação entre diferentes temporalidades e fazeres, que se liga ao modo de transmissão das influências e que se dá entre moças de família, mulheres de "bom 


\section{INFLUENCIADORAS DE MODA EM VITÓRIA DA CONQUISTA, BAHIA, BRASIL: CONTINUIDADES E DESCONTINUIDADES}

gosto", entre estas e influenciadoras digitais de moda conquistenses e entre estas e webcelebridades. Ou seja, as redes de influência se dão no agora, ao mesmo tempo em que se prolongam numa história, feita, portanto, de continuidades (e, familliaridade) e descontinuidades (novidades, mas que não chegam, necessariamente, a funcionar como rupturas radicais).

Oportunamente, Bourdieu nos ajuda a refletir sobre a questão das continuidades e descontinuidades no modo de influenciar de agentes nacionalmente famosas, pois ao mesmo tempo em que reproduzem um estilo de vida de celebridades e acabam se tornando pessoas de referência de bom gosto, no que se refere às modas e modos também inauguram uma nova concepção de influência, na medida em que o fato de serem pessoas comuns, que não possuem nada de extraordinário, abre espaço para que um maior número de indivíduos possa reproduzir esse comportamento, acreditando que também podem produzir conteúdo que inspire outros traço que, juntamente com os avanços técnicos na direção da constituição de redes mais extensas e interativas, constitui a especificidade maior do momento atual em comparação às possibilidades de influência, antes muito mais restritas, de tempos pregressos. A grande novidade seria, então, o fato de que, no momento atual de frenesi com o ciberespaço, democratizou-se, em certa medida, a possibilidade de ser referência em algum assunto, pois se existem os posts de moda aqui analisados, existem outros perfis que focam em variados assuntos, como viagens, gastronomia, fotografia, cinema, entre outros - o que tem feito com que a profissionalização se torne crescentemente requisito ao sucesso (ou à manutenção do mesmo).

\section{CONSIDERAÇÕES FINAIS}

A partir do que foi abordado ao longo deste artigo, podemos salientar algumas questões interessantes no que concerne à relação entre moda e mídias sociais. Remetemo-nos às influenciadoras digitais de moda conquistenses e às moças de família da década de 1950-1960 também do município com o objetivo de perceber, a partir desse microcosmo, como se dá a internalização de um habitus e sua externalização enquanto prática. Assim, estabelece-se o elemento de continuidade e descontinuidade que permite falar em memória e perceber essas moças da Vitória da Conquista de hoje como continuidade em relação às moças de família de décadas passadas, sem que se confundam com elas, ao mesmo tempo em que se mostram como 


\section{INFLUENCIADORAS DE MODA EM VITÓRIA DA CONQUISTA, BAHIA, BRASIL: CONTINUIDADES E DESCONTINUIDADES}

continuidade em relação às influencers nacionais, mas igualmente sem se confundirem com elas.

São lugares ocupados na teia social que se desdobram no espaço e no tempo e que, portanto, não podem ser lidos como mera transmissão ou imitação de modos de vestir. Assim, a memória se refere não apenas a conteúdos transmitidos, mas também a modos de transmissão que dizem respeito a conteúdos específicos e, acima de tudo, a disposições. Tais disposições (habitus), por sua vez, se referem a práticas: modos de instituir influenciadores, modos de ser influenciador, modos de articular referências (como as das webcelebridades nacionais atualizadas para o contexto conquistense) e fazer sobreviver modos de atuar socialmente e gostos.

Quando as moças de família e as digital influencers afirmam possuir referências tanto nos modos quanto nas modas, não é apenas a saia plissada ou o sapato de bico quadrado que duram no tempo, na memória, nas práticas, mas a transmissão de um modo de vida a partir de meios de socialização trazidos pela moda e de maneiras de controle para que os grupos se mantenham coesos, pois a escolha por participar desses grupos não seria neutra, mas eivada das influências da estrutura social em que vivemos e que atuam para se autoreproduzirem.

\section{REFERÊNCIAS}

BOURDIEU, P. A distinção: crítica social do julgamento. Tradução Daniela Kern; Guilherme J. F. Teixeira. São Paulo: Edusp; Porto Alegre, RS: Zouk, 2007.

ORTIZ, R. As celebridades como emblema sociológico. Sociol. Antropol. [?], Rio de Janeiro, v. 06, no 03, p.669-697, dezembro, 2016.

SILVA, D. P. Fontes para a história social do trabalho: Vitória da Conquista e região. A economia regional nas fontes da Justiça do Trabalho (1963-1965). In: Ciclo de Estudos Históricos da UESC. 14 e 16 de setembro de 2009. Disponível em:

<http://www.uesc.br/eventos/cicloshistoricos/anais/danilo_pinto_da_silva.pdf >. Acesso: 10 jun. 2020.

SIMMEL, G. Filosofia da moda e outros escritos. Lisboa: Texto \& Grafia, 2008.

SOUZA, B. J. Arreios, currais e porteiras: uma leitura da vida política em Conquista na Primeira República. 1999. 177 f. Dissertação (Mestrado em Ciências Sociais). Pontifícia Universidade Católica de São Paulo, São Paulo. 1999.

\section{NOTAS}

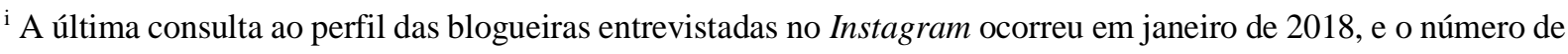
seguidores foi atualizado até essa data.
} 